\title{
SCHEMATA (BACKGROUND KNOWLEDGE) AND READING COMPREHENSION FOR EFL STUDENTS
}

\author{
By \\ Mahfood Al Salmi \\ Ministry of Education - Administration of Education Taif \\ English Language Supervisor
}

Research Gournal Specific Fducation

Faculty of Specific Fducation

SMansoura University

ISSUE NO. 22, JUL. 2011

مجلة بحوث التربية النوعية - جامعة المنصورة

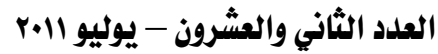




\title{
SCHEMATA (BACKGROUND KNOWLEDGE) AND READING COMPREHENSION FOR EFL STUDENTS
}

\author{
By \\ Mahfood Al Salmi \\ Ministry of Education - Administration of Education Taif \\ English Language Supervisor
}

\begin{abstract}
The impact of schema theory on reading comprehension process has been tremendous. Schema theory describes the process by which readers combine their own background knowledge with the information in a text to comprehend that text. All readers carry different schemata (background information) and these are also often culture-specific. This is an important concept in ESL teaching, and prereading tasks are often designed to build or activate the learners' schemata. This paper summarizes some of the research into schema theory and its applications to ESL reading comprehension.
\end{abstract}

Key words: schema theory, background knowledge, reading comprehension, EFL. 


\title{
SCHEMATA (BACKGROUND KNOWLEDGE) AND READING COMPREHENSION FOR EFL STUDENTS
}

\author{
$B y$ \\ Mahfood Al Salmi \\ Ministry of Education - Administration of Education Taif \\ English Language Supervisor
}

\section{Introduction}

Most discussions on schema theory have provided of the great importance of background knowledge in reading comprehension (Anderson et al 1986).

Schema theory is based on the belief that "every act of comprehension involves one's knowledge of the world as well" (Anderson et al in Carrell and Eisterhold, 1983:73). Thus, readers develop a coherent interpretation of text through the interactive process of "combining textual information with the information a reader brings to a text" (Widdowson in Grabe 1988:56). Readers' mental stores are termed 'schemata' (after Bartlett in Cook, 1997:86) and are divided (following Carrell 1983a) into two main types: 'content schema' (background knowledge of the world) and 'formal schemata' (background knowledge of rhetorical structure).

Schema-theoretic research highlights reader problems related to absent or alternate (often culture specific) schemata, as well as no-activation of schemata, and even overuse of background knowledge.

Carrell, Devine and Eskey (1988:4) claim that schema theory has provided numerous benefits to EFL teaching and, indeed, most current EFL textbooks attempt schema activation through prereading activities. However, there may be limits to the effectiveness of such activities and there may even have been some over-emphasis of the schema perspective and neglect of other areas (see Eskey 1988, McCarthy, 1991).

\section{Reading Comprehension}

Any reader of NL/SL/FL strives to understand what he is reading. Regardless of his purpose while approaching the text, it is usually meaning extraction which he aims at. Inside a text, there is a message encoded by a writer. The latter directs it to a particular audience of readers. If this 
audience does not get the writer's intended message, there will be no sense of both the writing process and the reading one. The writer will not achieve his goal to be read and understood and the reader will not profit from the writer and consequently, will not gain new insights to knowledge. Ur (1996: 138) reports that the essence of reading is understanding and that a foreign language learner who reads the words, but fails to understand them is, in fact, not reading. He is just about finding sound letter correspondences of the text's words without making any meaning. The centrality of understanding while reading was also emphasized by Nuttal (1982: 22) when she states: "understanding is central to the process of reading...". She (op.cit.) explains that "...(understanding) must be the focus of our teaching." Thus, someone who succeeds to decode the text is not necessarily understanding it. Since comprehension is the criterion which declares success or failure with the reading act, reading theorists call for the necessity of ensuring reading instruction with a focus on comprehension.

Reading comprehension is not only a matter of understanding the print on page but, it is the creation of meaning by combining what the print tells with what the reader already possesses as knowledge. To achieve comprehension, it is crucial for the reader to make use of his previous experiences. Wray (2004:14) views reading comprehension as an interaction between what the text provides and what the reader brings to it when he states:

Understating in reading is exactly like this. It is not simply a question of getting meaning from what is on the page. When you read, you supply a good deal of the meaning to the page. The process is an interactive one, with resultant learning being a combination of your previous ideas with new ones encountered in this text. Vaughn and Thompson (2004: 99) agree on the above-mentioned idea. They explain that reading comprehension is a dynamic construction of meaning. This meaning is the result of the combination of the text's input, the reader's prior knowledge, manipulation of lexis, making inferences and relating thoughts.

In other words, the reader should be creatively engaged otherwise he runs the risk of misinterpreting or misunderstanding the message at hand. Grellet (1981: 7) points also to this idea when she claims that the importance of what the reader brings to the text is greater than what he finds in it. 
It is worth mentioning that reading comprehension is difficult to measure. Reading theorists point out that the amount of comprehension is something which is difficult to be quantified. There are no standard criteria or scales which declare the reader's success in fully understanding the text or fully failing to comprehend it.

Other reading theorists view that if the reader reports the text's content orally or in a written way or simply answers questions about it, he is likely to be judged as comprehending successfully the text (Swan, 1976: 1).On his part, Davies (1995: 24) claims "reading comprehension is usually measured by means of retrieval rate from memory.". This idea establishes confusion between the nature of comprehension and memory capacities.

It is not a rule of thumb that someone who remembers the text's content is necessarily someone who has understood its meaning. A reader may memorize a Shakespearian soliloquy or a piece of prose without even knowing the meaning it conveys. Thus, memorization or remembering differs from understanding. For Alderson (2000: 7), reading comprehension occurs when the reader remembers the input gained from the text without being back in it for confirmation but, at the same time, he explains how this idea denies the existing difference between remembering and understanding. In contrast, Smith (2004: 60) defends the idea that reading comprehension cannot be measured in all cases. He writes: " Comprehension cannot be measured in the way that some aspects of information can. Comprehension cannot be measured at all, despite constant educational efforts to do so, because it is not a quantity of anything. Comprehension does not have dimension or weight; it is not incremental. Comprehension is not the opposite of uncertainty or even ignorance, and therefore is not quantifiable as the accumulation of a number of facts or items of information" . Comprehension is an abstract process. It cannot be treated as a concrete matter to be counted. Moreover, attempts to measure it are recognized as relative ones. They fail to report real insights of what is judged as understanding or misunderstanding.

Understanding a text differs from one reader to another. It is impossible that readers gain an identical meaning from the same text. The writer will not be physically present to explain what he meant by the point discussed on a page.

Thus, every reader provides his own meaning according to his own previous knowledge. None can judge his own interpretation to be the one 
meant by the writer. Therefore, the meaning derived by the reader is a relative one. There will be no single interpretation. Alderson and Urquhart (1984: 63) point that those who consider understanding as a process of building a given meaning for the text are in fact mistaken; for the simple reason that, there is no sole meaning but a number of possible meanings.

\section{THE SCHEMA THEORY OF READING}

\subsection{The definition of schema}

The basic premise of schema theory is that text is ambiguous. As Carrell and Eisterhold (1983) write, “... text, any text, whether written or spoken, does not by itself carry meaning. Rather, according to schema theory, a text only provides directions for listeners or readers as to how they should retrieve or construct meaning from their own, previously acquired knowledge" (p 76).

Thus, our background knowledge affects our interpretation of the text. To illustrate, let me provide these two examples.

a) The car was too expensive.

b) The coffee was too expensive.

Our interpretation of the word 'expensive' in sentence (a) is likely to be very different from our interpretation of the same word in sentence (b). From our life experiences we know the typical price of a car as well as the typical price of an expensive car, and we know expensive coffee, in a normal world, will always be cheaper.

Anderson and Pearson (1984), citing a study done by Halff, Ortony and Anderson (1976), write that a person's interpretation of the color red is different in each of the following compounds: red strawberry, red barn, red sunset and red hair ( $\mathrm{p}$ 52). Thus, our background knowledge, and the context in which the word is placed, affects our interpretation of that word.

Further, our interpretation of text is influenced by what we have read before. Notice how the sentence, 'He didn't have enough money', can be interpreted differently in the following examples.

c) The car was too expensive. He didn't have enough money

d) The coffee was too expensive. He didn't have enough money 
In sentence (c), 'He didn't have enough money', is likely to be interpreted as he didn't have enough savings, whereas in sentence (d) he probably has enough money at home or in the bank, but he doesn't have enough money on him right now.

From the above definitions, we may conclude that schema is the prior knowledge gained through experiences stored in one's mind. It is an abstract structure of knowledge.

\subsection{Types of schema}

Generally, there are three major types of schemata, namely, linguistic schemata, formal schemata and content schemata, which are closely related to reading comprehension.

\subsubsection{Linguistic schemata}

Linguistic schemata refer to readers' existing language proficiency in vocabulary, grammar and idioms. They are the foundation of other schemata. As is known, linguistic knowledge plays an essential part in text comprehension. Without linguistic schemata, it is impossible for the reader to decode and comprehend a text.

Therefore, the more linguistic schemata a reader has in his mind, the faster the reader acquires information and the better understanding the reader may get.

\subsubsection{Formal schemata}

Formal schemata are the organizational forms and rhetorical structures of written texts. They include knowledge of different text types and genres, and also include the knowledge that different types of texts use text organization, language structures, vocabulary, grammar and level of formality differently. Formal schemata are described as abstract, encoded, internalized, coherent patterns of meta-linguistic, discourse and textual organization that guide expectation in our attempts to understand a meaning piece of language. Readers use their schematic representations of the text such as fictions, poems, essays, newspaper articles, academic articles in magazines and journals to help comprehend the information in the text. Studies show that the knowledge of what type and genre the text is can facilitate reading comprehension for readers because the type of the text will offer detailed evidence of the content of the text. Nonetheless, compared 
with the linguistic and content schemata, the formal schemata offer less power in the reading process (Carrell, 1984).

\subsubsection{Content schemata}

Content schemata refer to the background knowledge of the content area of a text, or the topic a text talks about. They include topic familiarity, cultural knowledge and previous experience with a field. Content schemata deal with the knowledge relative to the content domain of the text, which is the key to the understanding of texts. Since one language is not only the simple combination of vocabulary, sentence structure and grammar but also the bearer of different levels of the language's culture. To some extent, content schemata can make up for the lack of language schemata, and thus help learners understand texts by predicting, choosing information and removing ambiguities.

Many studies show that readers' content schemata influence their reading comprehension more greatly than formal schemata. On the whole, the familiarity of the topic has a direct influence on readers' comprehension. The more the reader knows about the topic, the more easily and quickly he gets the information of the text. Therefore, if one wants to be an efficient reader, he needs to try to know the knowledge about more fields and topics. Learners with more prior knowledge can better comprehend and remember more the text.

\section{Schema theory and reading comprehension}

From the analysis above, it is clearly seen that schema plays an important role in reading comprehension. The author then will introduce three models of reading process and analyze the relationship between schema and reading comprehension.

\subsection{Models of reading process}

Psychologists have generally distinguished three kinds of processing: bottom-up model, top-down model and interactive model.

\subsubsection{Bottom-up model}

Bottom-up model of reading process holds the view that reading is a process of building symbols into words, words into sentences and sentences into the overall meaning, which reflects traditional attitudes toward reading. In this model, readers begin with the lowest level, from which the symbols 
are identified. Strings of symbols are then analyzed into morphological clusters, from which words are recognized and then strings of words are analyzed into phrases and sentences. The meaning of the text is expected to come naturally as the code is broken based on the reader's prior knowledge of linguistic units like vocabulary, grammar, syntax.

Therefore, from the point of view of bottom-up model, accuracy in understanding linguistic units is very significant and the lower-level processing skills in reading are important. This model weakens the significance of reading comprehension because the focus is on the understanding of linguistic knowledge but little attention is paid to schema, i.e. related cultural background, the whole text, etc.

\subsubsection{Top-down model}

Top-down model emphasizes the use of readers' real world knowledge in memory. The most influential and comprehensive top-down model is put forward by Kenneth S. Goodman (1967), "The goal of reading is constructing meaning in response to text; it requires interactive use of grapho-phonic, syntactic, and semantic cues to construct meaning." Readers do not read every word, but see through the text in order to be able to guess the meaning of the words or phrases. During this model reading process, readers take in larger units of meaning of the text at a time, match what they already know with the meaning they derive from the text. Top-down processing occurs as the system makes general predictions based on higher level and general schemata. It searches the input for information to fit into these partially satisfied, higher order schemata.

\subsubsection{Interactive model}

From the discussion above, it can be concluded that both bottom-up and top-down models have limitations. The recognition of this results in a more comprehensive reading process, namely, interactive model which is an interaction of bottom-up and top-down models claiming that prior knowledge and prediction facilitate the processing of input from the text. The interaction in this perspective takes place at three levels: 1)the interaction between lower-level and higher-level skills; 2)between bottomup processing and top-down processing; 3)between the background knowledge presupposed in the text and the background of the reader.

In interactive reading processing, both bottom-up and top-down processing should be occurring at all levels simultaneously (Rumelhart, 
1980). Readers may employ bottom-up process as a base for comprehending a text and then turn to top-down process to execute high-level interpretation of the content of the text. Prediction of the content will be confirmed, revised or rejected through further data analysis. Interactive model of reading process is the combination of bottom-up and top-down models, and thus absorbs their merits and avoids the limitations to a great extent. Till now, this is the most effective reading processing. Hence, it is advocated by many researchers.

\subsection{The three types of schemata and reading comprehension}

The importance of schematic knowledge is now widely acknowledged in foreign language teaching and many researches in the schema-oriented realm of ESL/EFL reading have been carried out. The relationship of the three types of schemata and reading comprehension will be introduced respectively in the following text.

\subsubsection{Linguistic schemata and reading comprehension}

As mentioned before, linguistic schemata refer to readers' existing language proficiency in vocabulary, grammar and sentence structure. As the basis of comprehension, language knowledge plays an important role on understanding of the text, especially for learners at the elementary stage of learning. Without basic language knowledge, no reading strategy or skill can function effectively. Therefore, the more language schemata readers have in their mind, the more information readers may acquire from the text, and the more effective readers they may become.

\subsubsection{Formal schemata and reading comprehension}

Formal schemata refer to the organizational forms and rhetorical structures of written texts, including knowledge of different text types and genres, and the acknowledgement that different types of texts use text organization, language structures, vocabulary, grammar and level of formality differently.

Carrel (1984) made an experiment to investigate whether we can facilitate ESL/EFL reading comprehension by teaching text structure based on schematic knowledge. The result of the experiment proved that explicit teaching of the text structure can improve students' reading comprehension. Different reading materials bear different characteristics and pose the 
correspondent reading requests for readers. A suitable employment of formal schemata plays a significant role in reading.

\subsubsection{Content schemata and reading comprehension}

Content schemata refer to the knowledge relative to the content domain of reading materials, which is the key to the understanding of a text. As a language is not only consisted of vocabulary, grammar and sentence structures, it is also the carrier of different levels of culture. Studies proved that content schemata affect comprehension and remembering more than formal schemata do for text organization. Readers remembered the most when both the content and rhetorical forms were familiar to them while unfamiliar content may cause more difficulties in correct comprehension.

\section{IMPLICATIONS FOR TEACHING READING TO EFL STUDENTS}

EFL teachers can apply insights from the schema theory research to classroom reading instruction. Two strategies for teaching reading will be discussed. They are pre-reading activities and narrow reading.

\subsection{Pre-reading activities}

Pre-reading activities are an excellent way for students to draw on their current knowledge and develop schemata prior to reading a given text. Connections between details and the overall structure of a particular schema are explored in class before students do any reading. The technique can be as simple as brainstorming on the blackboard. The teacher writes a keyword on the blackboard and then elicits associated words from the students. If all goes as planned, lines are drawn on the blackboard between words and a network of connections becomes apparent to the students as they participate in the brainstorming activity. While doing this, the teacher has a chance to gage the students' level of schematic knowledge about the topic. After the blackboard is full of networked information, the teacher can draw the students' attention to the student-generated associations that are most relevant to the reading that will follow. This simple activity need not be limited to words. Photos and drawings can be used too.

This procedure provides a visual representation of the important schematic associations needed to comprehend a story; it allows for cultural differences (if any) between the reader's mother culture and the reading 
passage's source culture to be to be identified and discussed before any reading is done.

Pre-reading is an excellent classroom activity, but it in no way guarantees reading success. It may be that a particular text is simply too difficult for a group of students; the text may require schematic knowledge beyond the students' current understanding.

\subsection{Narrow Reading}

For lower level learners or any student population that finds reading in English particularly challenging, it makes sense to initially limit unfamiliar content in texts as much as possible until students achieve a level of automaticity (Eskey and Grabe, 1988) in word and phrase recognition (p. 235). Stephen Krashen has advocated "narrow reading." Narrow reading is extensive reading in one area of the reader's choice. Krashen maintains that this technique will help students develop richer vocabularies and more elaborate schemata (p. 339). Students doing narrow reading are encouraged to read about content that is already familiar to them in their mother tongue. Thus the EFL learner can develop fluency in English language reading without being encumbered by a text overloaded with unfamiliar content.

\section{Conclusion}

Schema theory asserts that the reader, his or her background knowledge, and the content of a given text are the core components of the reading process. Schema theory suggests that EFL teachers need to be aware of the content and embedded cultural cues in texts and the potential difficulty they pose to the EFL learner. Whereas traditional approaches to teaching reading have focused almost exclusively on the text, schema theory implies that the scope should be broadened to include both the text and the reader's background knowledge.

However, it has been seen that schema-theoretic applications do not always result in improvements in comprehension, particularly where they result in insufficient attention to textual detail, or where there is an increase in schema-interference by, for example, the activation of dominant or negative schemata. 


\section{References}

- Anderson, R.C., \& Pearson, P.D. (1984). 'A Schema-Theoretic View of Basic Processes in Reading Comprehension.' In P.D. Pearson, R. Barr, M.L. Kamil, \& P. Mosenthal (Eds.). The Handbook of Reading Research (pp. 255-292). New York: Longman.

- Carrell, P. L. (1984). The effects of Rhetorical Organization on ESL Readers. TESOL Quarterly, 18.

- Carrell, P.L. and Eisterhold, J.C. (1983) "Schema Theory and ESL Reading Pedagogy", in Carrell, P.L., Devine, J.

- Eskey, D.E. (1988) "Holding in the Bottom: an Interactive Approach to the Language Problems of Second Language.

- Goodman, K. S. (1967). Reading: A Psycholinguistic Guessing Game. Journal of Reading Specialist, (4).

- Grabe, W. (1988) "Reassessing the Term 'Interactive'", in Carrell, P.L., Devine, J. and Eskey, D.E. (eds.).

- Smith,f. (2004). Understanding Reading. New Jersey: Lawrence Erlbaum Associates,Inc. 


\section{هلخص البحث}

إن تأثير النظرية التخطيطية على استيعاب و إدراك مهارة القراءة يعد تأثير هائل· إن هذه

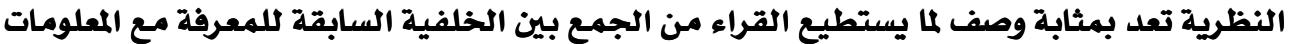

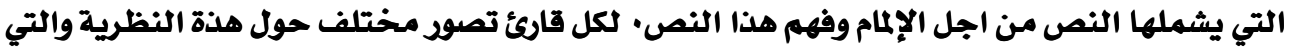

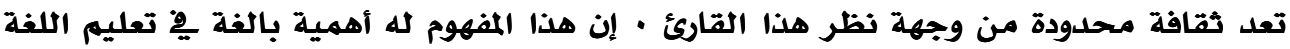

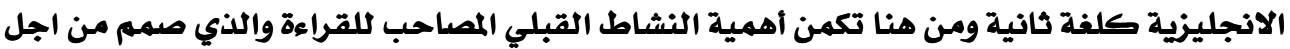
بناء أو تفعيل هذة النظرية للمتعلم، ويعتبر هذا البحث هو تلخيص التهن للعديد من الأبحاث التي تهتم

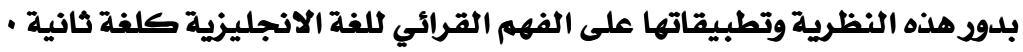

